(c) American Dairy Science Association, 2005.

\title{
Frequency of Feed Delivery Affects the Behavior of Lactating Dairy Cows
}

\author{
T. J. DeVries, ${ }^{1}$ M. A. G. von Keyserlingk, ${ }^{1}$ and K. A. Beauchemin ${ }^{2}$ \\ ${ }^{1}$ Animal Welfare Program, The University of British Columbia, 2357 Main Mall, \\ Vancouver, BC, V6T 1 Z4 Canada \\ ${ }^{2}$ Agriculture and Agri-Food Canada, Research Centre, Lethbridge, AB, T1J 4B1 Canada
}

\begin{abstract}
The objectives of this study were to examine how frequency of feed delivery affects 1) the behavior of group-housed and group-fed dairy cows and 2) the extent of feed sorting. These objectives were tested in two experiments. In each experiment, 48 lactating Holstein cows, split into groups of 12 , were subjected to each of 2 treatments (over 10-d periods) in a cross-over design. The treatments for the first experiment were 1) delivery of feed once per day (1×) and 2) delivery of feed twice per day $(2 \times)$. Treatments for the second experiment were 1) delivery of feed $2 \times$ and 2 ) delivery of feed four times per day $(4 \times)$. For the $1 \times, 2 \times$, and $4 \times$ treatments, feed was pushed up 3,2 , and 0 times per day, respectively. For both experiments, cows had $0.6 \mathrm{~m}$ of feeding space; one cows was allowed per lying stall. Time-lapse video was used to quantify the feeding and lying behavior, as well as the aggressive behavior displayed at the feed bunk by the cows. Changes in NDF content of the TMR throughout the day were used to determine the extent of feed sorting by the cows. In both experiments, increased frequency of feed provision increased, as well as changed, the distribution of daily feeding time. The changes in distribution of feeding time resulted in cows having more equal access to feed throughout the day. Frequency of feed delivery had no effect on the daily lying time of the cows or the daily incidence of aggressive interactions at the feed bunk. However, subordinate cows were not displaced as frequently when fed more often. For all treatments, in both experiments, the NDF content of the TMR present in the feed bunk increased throughout the day, indicating that sorting of the feed had occurred. Further, the amount of sorting of the feed was reduced by increasing the frequency of feed delivery from $1 \times$ to $2 \times$. These results indicate that frequent delivery of feed improves access to feed for all
\end{abstract}

Received May 3, 2005.

Accepted June 23, 2005.

Corresponding author: T. DeVries; e-mail: trevorjd@interchange. ubc.ca. cows, particularly during peak feeding periods when fresh feed is provided, and reduces the amount of feed sorting.

(Key words: frequency of feed delivery, feeding behavior, dairy cow)

Abbreviation key: $1 \times=$ feed delivery once a day, $\mathbf{2} \times=$ feed delivery twice a day, $4 \times=$ feed delivery 4 times a day.

\section{INTRODUCTION}

Considerable research to date has been focused on improving DMI of lactating dairy cows by changing the nutrient composition of feeds. However, the DMI of group-housed lactating dairy cows is also affected by feeding behavior, which is modulated by the environment, management, health, and social interactions (Grant and Albright, 2000). Previous research by our group indicated that both the management practice of feed delivery and the act of returning from milking stimulate feeding activity in cows (DeVries et al., 2003a). The delivery of feed was further shown to have the greatest impact in terms of stimulating dairy cows to feed (DeVries and von Keyserlingk, 2005).

The majority of lactating dairy cows in North America are fed a TMR offered ad libitum. Nocek and Braund (1985) suggested that feeding a TMR is the optimal way to provide the balance of nutrients that ruminants need to maintain a stable and efficient microbial population. These researchers also indicated that the availability of the feed over time and distribution of intake over the course of the day may further contribute to the maintenance of a stable ruminal microbial population. Provision of the TMR in conventional feeding schedules of lactating dairy cattle for most dairy operations remains at twice per day $(\mathbf{2} \times)$. However, many producers elect to feed their cows only once per day $(\mathbf{1} \times)$ to reduce labor costs. The feeding behavior response elicited by cows to the delivery of fresh feed may, therefore, result in slug feeding when feed is only provided $1 \times$, which could predispose a cow to subacute ruminal acidosis (Shaver, 2002). Because the delivery of feed stimulates 
feeding activity (DeVries and von Keyserlingk, 2005) and is also associated with increased aggressive behavior between animals (Jezierski and Podluzny, 1984), it follows that a low frequency of feed delivery may result in increased competition among cows. Furthermore, increased competition may lead to some cows modifying their feeding times to avoid aggressive interactions (Miller and Wood-Gush, 1991).

Alternatively, it could be hypothesized that with more frequent offerings of feed, the distribution of feeding time and intake would be more evenly spread throughout the day. Furthermore, a steady input of nutrients into the rumen over the course of the day would stabilize rumen pH (French and Kennelly, 1990), which may reduce the risk for subacute ruminal acidosis. There appears to be little work addressing the effects of frequency of feed delivery on the behavior of group-housed lactating dairy cattle, in particular, the distribution of daily feeding time and the level of competition at the feed bunk.

Questions can also be raised regarding the effect of frequency of feed delivery on the quality of the TMR available to the cows over the course of the day. Cows have been shown to sort preferentially for the grain component of a TMR, leaving the longer forage components. This behavior results in an increase in the fiber content of the remaining feed (Leonardi and Armentano, 2003), with the greatest effect thought to occur when frequency of feed delivery is low (Shaver, 2002).

Therefore, the first objective of this study was to examine how the frequency of feed delivery affects the behavior of group-housed lactating dairy cows. The second objective of this study was to examine how frequency of feed delivery affects the extent of feed sorting. These objectives were tested in 2 experiments. The first compared the effects of delivering feed $1 \times$ to $2 \times$, and the second compared the effects of delivering feed $2 \times$ to delivering feed 4 times a day $(\mathbf{4} \times)$.

\section{MATERIALS AND METHODS}

\section{Animals, Housing, and Diet}

Eleven primiparous and 37 multiparous (parity $=3.5$ \pm 1.3 ; mean $\pm \mathrm{SD}$ ) lactating Holstein dairy cows were used for 2 experiments. For the first experiment, the animals were $139.5 \pm 18.1 \mathrm{DIM}$ at the beginning of the data collection period and had an average milk yield of $42.5 \pm 8.5 \mathrm{~kg} / \mathrm{d}$ over the course of the experiment. For the second experiment, the animals were $165.5 \pm 18.1$ DIM at the beginning of the data collection period and had an average milk yield of $40.6 \pm 7.7 \mathrm{~kg} / \mathrm{d}$ over the course of the experiment. For both experiments, the animals were divided into 4 equal groups of 12 cows, which were balanced according to DIM, projected 305-
Table 1. Ingredient and chemical composition of the TMR.

\begin{tabular}{lcc}
\hline Composition & Experiment 1 & Experiment 2 \\
\hline Ingredient, \% of DM & & \\
Corn silage & 19.7 & 20.1 \\
Grass silage & 9.7 & 8.2 \\
Alfalfa hay & 8.8 & 8.6 \\
Third-cut grass hay & 10.6 & 10.9 \\
Barley-corn blend $^{1}$ & 14.6 & 14.9 \\
Concentrate ash $^{2}$ & 36.6 & 37.3 \\
Chemical analysis & \\
DM, \% & & \\
OM, \% of DM & 49.4 & 48.4 \\
CP, \% of DM & 92.0 & 91.7 \\
ADF, \% of DM & 18.5 & 18.7 \\
NDF, \% of DM & 20.3 & 19.6 \\
NDF from forages, \% of NDF & 36.2 & 35.2 \\
\end{tabular}

${ }^{1}$ Supplied by Unifeed Ltd. (Chilliwack, BC, Canada); contained 30\% steam-rolled corn and 70\% steam-rolled barley.

${ }^{2}$ Supplied by Unifeed Ltd.; contained $18 \%$ soybean meal, $14 \%$ barley, $13.2 \%$ steam-rolled barley, $12.0 \%$ rye-corn distillers, $11 \%$ Amipro (Unifeed Ltd., 9\% canola meal, $5 \%$ mill screenings, $3 \%$ cane molasses, $2.8 \%$ limestone, $2 \%$ tallow, $2.0 \%$ saturated vegetable fat, $1.5 \%$ trace mineral-vitamin premix, $1.3 \%$ fish meal, $1.2 \%$ Megalac (Church and Dwight Co., Princeton, NJ), 1.2\% sodium bicarbonate, $1.2 \%$ Yea-Sacc Farm Pak (Alltech, Inc., Nicholasville, KY), 1.0\% salt, $0.4 \%$ dicalcium phosphate, and $0.2 \%$ magnesium oxide.

${ }^{3}$ Values were obtained from chemical analysis of TMR samples.

$\mathrm{d}$ milk production $(11,409.4 \pm 1874.4 \mathrm{~kg})$, and average parity $(2.9 \pm 1.6)$. These groups were created by blocking cows into groups of 4 cows (similar in parity, DIM, and projected 305-d milk production) and then randomly assigning the cows in these blocks to 1 of the 4 experimental groups. All groups were housed together for 1 wk to allow for social adaptation prior to data collection in the first experiment. The cows remained together until the end of the second experiment. The experiments were conducted between January 18, 2004 and March 3, 2004. The average temperature during this experiment was $5.5^{\circ} \mathrm{C}$, with a minimum of $-10.5^{\circ} \mathrm{C}$ and maximum of $15.5^{\circ} \mathrm{C}$.

The cows were housed in a free-stall barn located at The University of British Columbia Dairy Education and Research Center (Agassiz, BC, Canada) and were managed according to the guidelines set by the Canadian Council on Animal Care (1993). In both experiments, cows were fed ad libitum a TMR (Table 1). In experiment 1, the TMR contained, on a DM basis, $51.2 \%$ concentrate and $48.8 \%$ forage; in experiment 2, the TMR contained, on a DM basis, $52.2 \%$ concentrate and $47.8 \%$ forage. Diets were formulated according to the NRC (2001) nutrient requirement recommendations for high-producing dairy cows. Cows had access to the feed bunk via a post-and-rail feed barrier (with a pendulous feed-rail) and had $0.6 \mathrm{~m}$ of feeding space per animal. In both experiments, feed push-ups occurred to ensure that feed was available to the cows for all hours in the day during which they were in their respective pen. 
Each cow had access to a free-stall that was deep bedded with sand. Animals were milked between 0500 and $0530 \mathrm{~h}$ in the morning and between 1700 and $1730 \mathrm{~h}$ in the afternoon. Milk yields were automatically recorded at each milking.

\section{Experimental Treatments and Design}

In experiments 1 and 2, the 48 lactating cows were used in a cross-over design. Each group was subjected to each of 2 treatments in each experiment. Initially, each of the 2 treatments was applied to 2 groups of cows for a 3-d adjustment period followed by $7 \mathrm{~d}$ of data collection. Treatments were then switched between the groups. Again, animals had a 3-d adjustment period followed by $7 \mathrm{~d}$ of observations on the new treatment. Because the groups were housed in adjacent pens, treatments were alternated between groups so that adjacent groups were always on different treatments.

Experiment 1. Treatments were 1) delivery of feed $1 \times($ at $0530 \mathrm{~h}$ ) and 2) delivery of feed $2 \times$ (at 0530 and $1515 \mathrm{~h}$ ). When groups were fed $1 \times$, feed was pushed up at 1100,1515 , and $2230 \mathrm{~h}$. When groups were fed $2 \times$, feed was pushed up at 1100 and $2230 \mathrm{~h}$.

Experiment 2. Treatments were 1) delivery of feed $2 \times$ (at 0530 and $1515 \mathrm{~h}$ ) and 2) delivery of feed $4 \times$ (at $0530,1100,1515$, and $2230 \mathrm{~h}$ ). When groups were fed $2 \times$, feed was pushed up at 1100 and $2230 \mathrm{~h}$. No feed push-up occurred when cows were fed $4 \times$.

In experiment 1 , for the $1 \times$ treatment, the TMR was mixed in the morning immediately prior to its delivery to the cows. For the $2 \times$ treatment, in both experiments, the TMR for the 0530-h feeding was mixed immediately prior to its delivery to the cows. The TMR for the 1515$\mathrm{h}$ feeding was mixed at approximately $1030 \mathrm{~h}$ and kept in the mixer wagon until the time of feed delivery. In experiment 2 , for the $4 \times$ treatment, the TMR was mixed twice daily. The TMR for the 0530 - and 1100 -h feedings was mixed immediately prior to the 0530 -h feeding. The TMR used in the 1100-h feeding was kept in the mixer wagon until the time of delivery. The TMR for the 1515and 2230-h feedings was mixed at approximately 1030 h. The TMR for the 1515-h feeding was then kept in the mixer wagon until the time of delivery; the TMR for the 2230-h feeding was stored in a bunker silo until approximately $1900 \mathrm{~h}$, at which time it was transferred to the mixer wagon and was kept there until it was delivered to the cows.

\section{Feed Sampling and Analysis}

For both experiments, representative samples of the TMR were taken for each group at the time of each feed delivery, feed push-up, and from the orts for $\mathrm{d} 1,3,5$, and 7 of each treatment period in each experiment. The TMR was subsampled by taking grab samples from 3 different locations along the entire feed bunk. Care was taken that each grab sample represented the top, middle, and bottom of the TMR along the feed bunk. Dry matter content of the samples was determined by ovendrying at $60^{\circ} \mathrm{C}$ for $3 \mathrm{~d}$. The dried samples were then ground to pass through a 1-mm screen (standard model 4 Wiley mill; Arthur H. Thomas Co., Philadelphia, PA). Analytical DM content of the samples was determined by drying at $135^{\circ} \mathrm{C}$ for $3 \mathrm{~h}$ (AOAC, 1990). The OM content was calculated as the difference between DM and ash contents; ash was determined by combustion at $550^{\circ} \mathrm{C}$ for $5 \mathrm{~h}$. The NDF and ADF contents were determined using an ANKOM $^{200}$ Fiber Analyzer (ANKOM Technology, Fairport, NY) according to the methodology supplied by the company, which is based on the methods described by Van Soest et al. (1991). Heat-stable $\alpha$ amylase and sodium sulfite were used in the NDF procedure. For the measurement of $\mathrm{CP}(\mathrm{N} \times 6.25)$, content of $\mathrm{N}$ in the samples was determined by flash combustion using a model NA 2100 Protein CHN Analyzer (Carlo Erba Instruments, Milan, Italy).

Dry matter intake for each group for each day on treatment was recorded by subtracting the DM weight of the orts from the DM weight of the delivered feed. The daily orts averaged $5.2 \pm 5.1 \%$ and $7.9 \pm 4.8 \%$ (mean $\pm \mathrm{SD}$ ) of the delivered feed provided over the course of experiments 1 and 2, respectively.

\section{Behavioral Recording}

All behaviors were monitored using time-lapse video equipment. The feeding and lying behavior of the cows were recorded continuously for $7 \mathrm{~d}$ per treatment. The aggressive behavior of the cows was recorded continuously for the last $3 \mathrm{~d}$ of the observation period for each treatment. The animals were videotaped using 2 video cameras (Panasonic WV-BP330; Osaka, Japan) per pen, a time-lapse videocassette recorder (Panasonic AG6540), and a video multiplexer (Panasonic WJ-FS 216). For each pen, a video camera was located $6 \mathrm{~m}$ above the feed bunk and another $10 \mathrm{~m}$ above the lying areas of the pen. Red lights (100 W) were used to facilitate recording at night. Individual animals were identified with unique alphanumeric symbols made with hair dye (Clairol's Nice and Easy \# 122, Natural Black, or Clairol's L'image Maxiblonde, depending on hair color; Stamford, CT) on the back of the cows.

Measuring feeding behavior. The feeding behavior of individual cows was scored from video using instantaneous scan sampling once every $10 \mathrm{~min}$. For each scan, an animal was recorded as feeding when its head was completely past the feed rail and over the feed. These 
scans were then used to calculate the total time spent feeding by multiplying the number of scans by 10 (Endres et al., 2005). The time spent feeding was calculated for each cow for each treatment day. This measure of feeding behavior has previously been shown to be the most repeatable measure of feeding behavior and sensitive for detecting treatment differences (DeVries et al., 2003b). Additionally, to detect changes in the distribution of daily feeding time, we calculated the feeding time for the cows during the daytime and early evening hours ( 0600 to $2000 \mathrm{~h}$ ), the late evening and early morning hours (2000 to $0600 \mathrm{~h}$ ), and for the $90 \mathrm{~min}$ after the time of feed delivery, which was identified as a period of peak feeding activity.

Measuring lying behavior. Daily lying times of individual cows were obtained from the video recordings using instantaneous scan sampling once every $10 \mathrm{~min}$. These scans were then used to calculate the total time spent lying by multiplying the number of scans by 10 (Fregonesi et al., 2004). The time spent lying was calculated for each cow for each treatment day. In addition to this, the length of time it took cows to lie down upon return from the milking parlor (i.e., latency to lie) was obtained. This was quantified by continuously watching the video recordings from the time the cows returned from the parlor until they lay down in one of the free stalls.

Measuring aggressive behavior. Total daily number of aggressive displacements at the feed bunk was recorded. A displacement was noted when a butt or a push from the actor (instigator) resulted in the complete withdrawal of the reactor's head from beneath the feed rail (DeVries et al., 2004).

\section{Data Analysis}

For the analysis of feeding behavior, DMI, lying behavior, and aggressive behavior, pen was considered the experimental unit; measures from multiple days and cows were averaged to create one observation per pen per treatment. For experiment 1, there was an interaction between treatment and the milking time (i.e., a.m. or p.m.) for the latency-to-lie down data; consequently, these data were summarized and analyzed separately for each milking. Treatment effects on the feeding behavior measures, DMI, lying behavior measures, and number of displacements were tested by onesample paired $t$-tests with $3 \mathrm{df}$. Least squares means and standard errors were determined using the LSMEANS and STDERR statement in PROC GLM (SAS, 1999). Overall, treatment response was tested using pen as the experimental unit. However, we predicted that cows with low feeding times and cows that were displaced from feed bunk most often would be most affected by treatment; therefore, we used a withincow test to examine this assumption. Feeding times [for the 90 min after feed delivery and for the late evening and early morning hours (2000 to $0600 \mathrm{~h}$ )] and the frequency at which cows were displaced from the feed bunk during the 2 treatments, in each experiment, were compared using the regression procedure of SAS (1999). To determine whether cows changed on average, the intercept was tested for difference from zero, and to determine the extent of the change relative to the initial value, the slope was tested for difference from one.

For analysis of the NDF content of the TMR samples, pen was considered the experimental unit; measures from multiple days were averaged to create one observation per pen per treatment per sampling time. Treatment effects were tested in a mixed model. Compound symmetry was selected as the covariance structure on the basis of best fit using the PROC MIXED procedure of SAS (1999). Subsequent analyses were performed with PROC GLM, which uses the compound symmetry structure as a default and allowed us to model the sampling time as a continuous variable. The model tested the terms for pen ( $3 \mathrm{df})$, treatment ( $1 \mathrm{df})$, linear effect of sampling time ( $1 \mathrm{df}$ ), quadratic effect of sampling time ( $1 \mathrm{df})$, and the interaction between treatment and the quadratic effect of sampling time (1 df) against the residual error (32 df). Least squares means and standard errors were determined using the LSMEANS and STDERR statement in PROC GLM.

\section{RESULTS}

\section{Feeding Behavior and Feed Intake}

During experiment 1 , cows fed $2 \times$ increased their daily feeding time by 10 min compared with daily feeding time when they were fed $1 \times$ (Table 2 ). This increase was primarily attributed to the tendency for cows to increase their feeding time during the late evening and early morning hours (i.e., 2000 to $0600 \mathrm{~h}$ ). Linear regression was used to determine how individual cows changed their feeding times during these hours. Feeding times during this period were highly related for the 2 treatment conditions $\left(\mathrm{R}^{2}=0.54 ; P<0.001\right)$. The slope $(0.76 \pm 0.10)$ for the linear relationship was $<1(P=$ $0.02)$, and the intercept $(21.01 \pm 5.66)$ was $>0(P<0.001)$. Despite finding no difference in feeding time during the daytime and early evening hours, there were differences in the distribution of the feeding time during these times. Cows tended to spend more time feeding during the 90 min following delivery of feed when they were fed $1 \times$ than when they were fed $2 \times$ (Table 2 ). These differences are illustrated in the feed bunk attendance patterns (Figure 1a). Linear regression was used to determine how individual cows changed their feeding 
Table 2. Daily feeding time and feeding time during the daytime and early evening hours, during the late evening and early morning hours, and during the 90-min period following the delivery of feed for both treatments ${ }^{1}$ in experiments 1 and 2 .

\begin{tabular}{|c|c|c|c|c|}
\hline \multirow[b]{2}{*}{ Experiment 1} & \multicolumn{2}{|c|}{ Treatment } & \multirow[t]{2}{*}{$\mathrm{SE}$} & \multirow[t]{2}{*}{$P$} \\
\hline & $1 x^{2}$ & $2 \times^{2}$ & & \\
\hline $\begin{array}{l}\text { Daily, }{ }^{3} \mathrm{~min} / \mathrm{d} \\
\text { Daytime and early evening, }{ }^{4} \mathrm{~min} \\
\text { Late evening and early morning, }{ }^{5} \mathrm{~min} \\
\text { Delivery of fresh feed, }{ }^{6} \mathrm{~min}\end{array}$ & $\begin{array}{r}293.5 \\
243.0 \\
50.5 \\
51.2\end{array}$ & $\begin{array}{r}303.8 \\
244.6 \\
59.2 \\
44.9\end{array}$ & $\begin{array}{l}2.1 \\
2.9 \\
2.1 \\
2.0\end{array}$ & $\begin{array}{l}0.04 \\
0.73 \\
0.06 \\
0.11\end{array}$ \\
\hline Experiment 2 & $2 \times$ & $4 \times^{2}$ & & \\
\hline $\begin{array}{l}\text { Daily, } \min / \mathrm{d} \\
\text { Daytime and early evening, min } \\
\text { Late evening and early morning, min } \\
\text { Delivery of fresh feed, min }\end{array}$ & $\begin{array}{r}305.5 \\
253.4 \\
52.1 \\
48.9\end{array}$ & $\begin{array}{r}319.7 \\
251.0 \\
68.7 \\
40.5\end{array}$ & $\begin{array}{l}2.8 \\
3.8 \\
1.4 \\
1.4\end{array}$ & $\begin{array}{l}0.04 \\
0.68 \\
0.003 \\
0.02\end{array}$ \\
\hline $\begin{array}{l}{ }^{1} \text { Data were averaged for } 7 \mathrm{~d} \text { per treatr } \\
{ }^{2} 1 \times=\text { feed delivery once/d at } 0530 \mathrm{~h} ; 2 \\
\text { times/d at } 0530,1100,1515 \text {, and } 2230 \mathrm{~h} \\
{ }^{3} \text { Average feeding time/d per cow. } \\
{ }^{4} \text { Average feeding time per cow betwee } \\
{ }^{5} \text { Average feeding time per cow betwee }\end{array}$ & $\begin{array}{l}\text { groups } \\
\text { elivery } \\
\text { d } 2000 \\
\text { d } 0600\end{array}$ & $\begin{array}{l}2 \text { cows } \\
0530 \text { a }\end{array}$ & ). & ivery 4 \\
\hline
\end{tabular}

times during these peak feeding periods. Feeding times during this period were highly related for the 2 treatment conditions $\left(\mathrm{R}^{2}=0.51 ; P<0.001\right)$. The slope $(0.52$ $\pm 0.07)$ for the linear relationship was $<1(P<0.001)$, and the intercept $(18.40 \pm 4.04)$ was $>0(P<0.001)$.

When cows were provided feed $4 \times$ in experiment 2 , they increased their daily feeding time by $14 \mathrm{~min}$ compared with when they were fed $2 \times$ (Table 2). Most of this increase was the result of an increase in feeding time during the late evening and early morning hours. Linear regression was used to determine how individual cows changed their feeding times during these hours. Feeding times during this period were highly related for the 2 treatment conditions $\left(\mathrm{R}^{2}=0.46 ; P<\right.$ $0.001)$. The slope $(0.81 \pm 0.13)$ for the linear relationship was not different from one $(P=0.16)$, and the intercept $(26.27 \pm 7.33)$ was $>0(P<0.001)$. As in experiment 1 , despite finding no difference in feeding time during the daytime and early evening hours, there were differences in the distribution of the feeding time during these hours. Cows spent more time feeding during the 90 min following the delivery of feed when fed $2 \times$ than when fed $4 \times$ (Table 2). These differences are illustrated in the feed bunk attendance patterns (Figure 1b). Linear regression was used to determine how individual cows changed their feeding times during these peak feeding periods. Feeding times during this period were highly related for the 2 treatment conditions $\left(R^{2}=0.66\right.$; $P<0.001)$. The slope $(0.60 \pm 0.06)$ for the linear relationship was $<1(P<0.001)$, and the intercept $(11.19 \pm 3.27)$ was $>0(P=0.001)$.
There was no difference in DMI when groups were fed $1 \times$ compared with when they were fed $2 \times(24.6 \pm$ 0.7 vs. $24.1 \pm 0.7 \mathrm{~kg} / \mathrm{d}$ per cow, respectively; $P=0.7$ ). There was also no difference in DMI when groups were fed $2 \times$ compared with when they were fed $4 \times(22.9 \pm$ 0.4 vs. $22.2 \pm 0.4 \mathrm{~kg} / \mathrm{d}$ per cow, respectively; $P=0.3$ ).

\section{Lying Behavior}

During both experiments 1 and 2, the frequency of feed delivery had no effect on the length of time cows spent lying per day (Table 3 ). In experiment 1 , there was no effect of treatment on the pattern of lying time throughout the day (Figure 2a), but when cows were fed $1 \times$, they took longer to lie down after the a.m. milking compared with when they were fed $2 \times$ (Table 3 ). In experiment 2 , the pattern of lying time throughout the day was affected by the frequency of feed delivery. When cows were fed $4 \times$, they showed 4 periods of lying activity compared with the 2 extended periods of lying activity when they were fed $2 \times$ (Figure $2 b$ ). It is also interesting to note that when the cows received feed $4 \times$, they had a decreased latency to lie down after milking compared with when they were fed $2 \times$ (Table 3 ).

\section{Aggressive Behavior}

In experiment 1 , there was no difference in the frequency of displacements at the feed bunk when cows were fed $1 \times$ compared with $2 \times(9.6$ vs. 8.7 displacements/d per cow; $\mathrm{SE}=0.7 ; P=0.4)$. Linear regression indicated that the frequency of displacements was 

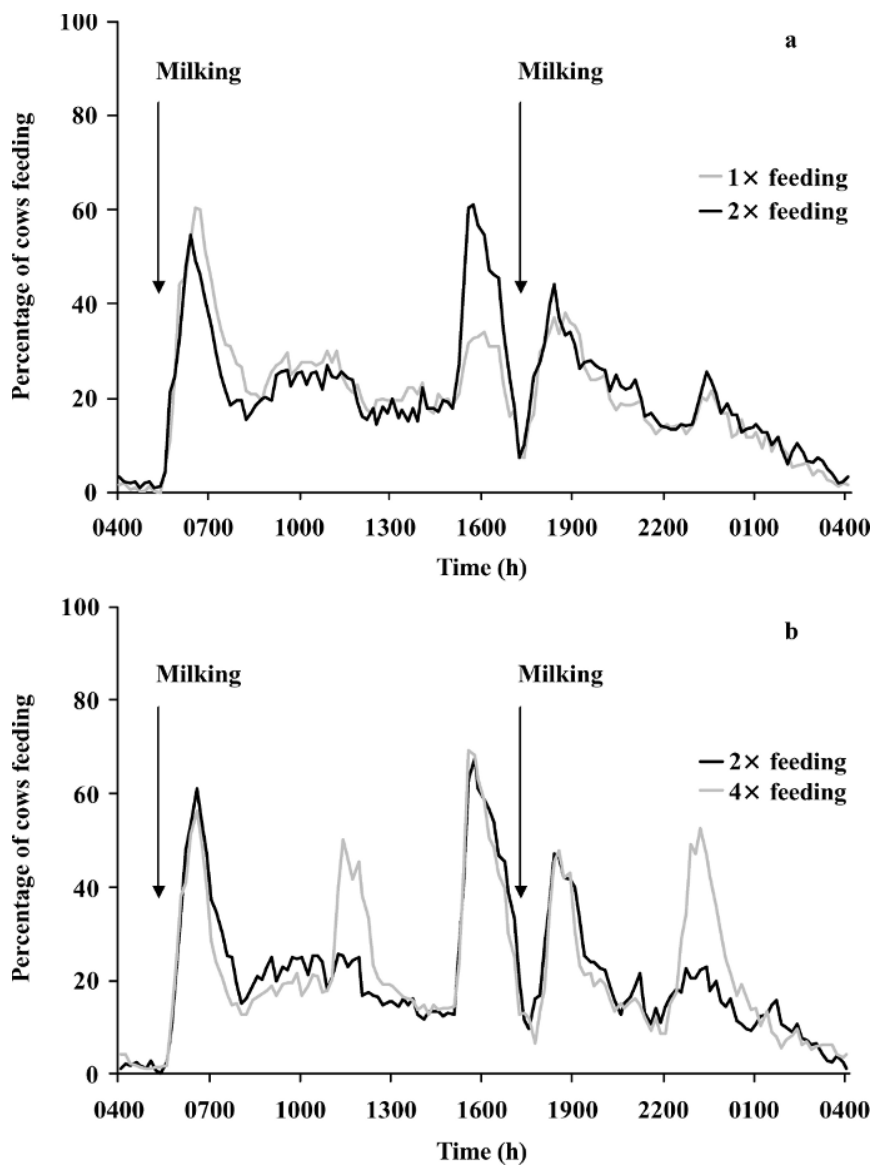

Figure 1. Percentage of cows per group present at the feed bunk over a 24-h period (percentage for each 10-min interval during the day) in a) experiment 1 for 2 treatments (cows fed at $0530 \mathrm{~h}$ and cows fed at 0530 and $1515 \mathrm{~h}$ ) and b) experiment 2 for 2 treatments (cows fed at 0530 and $1515 \mathrm{~h}$ and cows fed at $0530,1100,1515$, and $2230 \mathrm{~h}$ ). Data are averaged for $7 \mathrm{~d}$ per treatment of 4 groups, each containing 12 cows.

highly related for the 2 treatments $\left(\mathrm{R}^{2}=0.60 ; P<0.001\right)$ and varied between cows depending on treatment. The slope $(0.70 \pm 0.08)$ for the linear relationship was $<1(P<$ $0.001)$, and the intercept $(1.97 \pm 0.93)$ was $>0(P=0.04)$.

Similarly, for experiment 2 , there was also no difference in the frequency of displacements at the feed bunk when cows were fed $2 \times$ compared with $4 \times$ (7.5 vs. 7.7 displacements/d per cow; $\mathrm{SE}=1.1 ; P=0.9$ ). Linear regression for this experiment also indicated that the frequency of displacements was highly related for the 2 treatments $\left(\mathrm{R}^{2}=0.43 ; P<0.001\right)$ and varied between cows depending on treatment. The slope $(0.64 \pm 0.11)$ for the linear relationship was $<1(P=0.002)$, and the intercept $(2.94 \pm 0.96)$ was $>0(P=0.004)$.

\section{Fiber Content of the TMR}

For experiment 1 , analysis of NDF content of the TMR over the day indicated no effect of treatment; how-
Table 3. Mean time spent lying per day and the latency to lie after the return from milking for both treatments ${ }^{1}$ in experiments 1 and 2

\begin{tabular}{lllll}
\hline & \multicolumn{2}{c}{ Treatment } & SE & $P$ \\
\hline Experiment 1 & $1 \times^{2}$ & $2 \times^{2}$ & & \\
\cline { 2 - 3 } & 13.1 & 13.0 & 0.2 & 0.9 \\
Lying time, ${ }^{3}$ h/d & 70.7 & 57.7 & 1.7 & 0.01 \\
Latency to lie in a.m. ${ }^{4}$ min & 52.8 & 60.7 & 1.9 & 0.5 \\
Latency to lie in p.m., ${ }^{5}$ min & 62.9 & & \\
Experiment 2 & $2 \times$ & $4 \times^{2}$ & & \\
\cline { 2 - 4 } & 12.9 & 12.9 & 0.2 & 0.9 \\
Lying time, h/d & 66.2 & 55.2 & 1.9 & 0.03 \\
\hline
\end{tabular}

${ }^{1}$ Data were averaged for $7 \mathrm{~d}$ per treatment of 4 groups of cows (12 cows per group).

${ }^{2} 1 \times=$ feed delivery once/d at $0530 \mathrm{~h} ; 2 \times=$ feed delivery twice/d at 0530 and $1515 \mathrm{~h} ; 4 \times=$ feed delivery 4 times/d at 0530, 1100, 1515, and $2230 \mathrm{~h}$.

${ }^{3}$ Average lying time/d per cow.

${ }^{4}$ Length of time cows took to lie down after returning from being milked in the a.m.

${ }^{5}$ Length of time cows took to lie down after returning from being milked in the p.m.

${ }^{6}$ Length of time cows took to lie down after returning from being milked.

ever, there was an effect of sampling time (linear effect: $P<0.001$; quadratic effect: $P=0.003)$. Further, there was an interaction $(P=0.017)$ between treatment and the quadratic effect of sampling time, which indicated that the NDF content of the TMR in the feed bunk increased in a curvilinear manner throughout the day for both the $1 \times\left(\mathrm{y}=0.53 \mathrm{x}^{2}-1.57 \mathrm{x}+35.78 ; \mathrm{R}^{2}=0.98\right)$ and $2 \times\left(y=0.39 x^{2}-1.58 x+36.62 ; R^{2}=0.83\right)$ treatments; however, the effect was greatest when feed was delivered $1 \times$ (Figure $3 a)$.

Similarly in experiment 2, analysis of NDF content indicated no effect of treatment, but there was an effect of sampling time (linear effect: $P<0.001$; quadratic effect: $P=0.019$ ). Again, this indicated that the NDF content of the TMR in the feed bunk increased in a curvilinear manner throughout the day for both the $2 \mathrm{x}$ $\left(\mathrm{y}=0.39 \mathrm{x}^{2}-1.28 \mathrm{x}+34.86 ; \mathrm{R}^{2}=0.71\right)$ and $4 \times\left(\mathrm{y}=0.34 \mathrm{x}^{2}\right.$ $\left.-1.22 x+35.23 ; R^{2}=0.75\right)$ treatments (Figure $3 b$ ).

Changes in the forage-to-concentrate ratio of the TMR were estimated by calculating the forage-to-concentrate ratio of the orts. This calculation was performed using the initial NDF content values for the feed components and the final NDF content of the orts. In experiment 1 , the TMR for both $1 \times$ and $2 \times$ treatments initially had a forage-to-concentrate ratio, on a DM basis, of 49:51; however, the remaining orts for the $1 \times$ and $2 \times$ treatments had a calculated ratio of $63: 37$ and $55: 45$, respectively. In experiment 2 , the TMR for both $2 \times$ and $4 \times$ treatments initially had a forage-to-concentrate ratio, on a DM basis, of 48:52. The orts were calcu- 

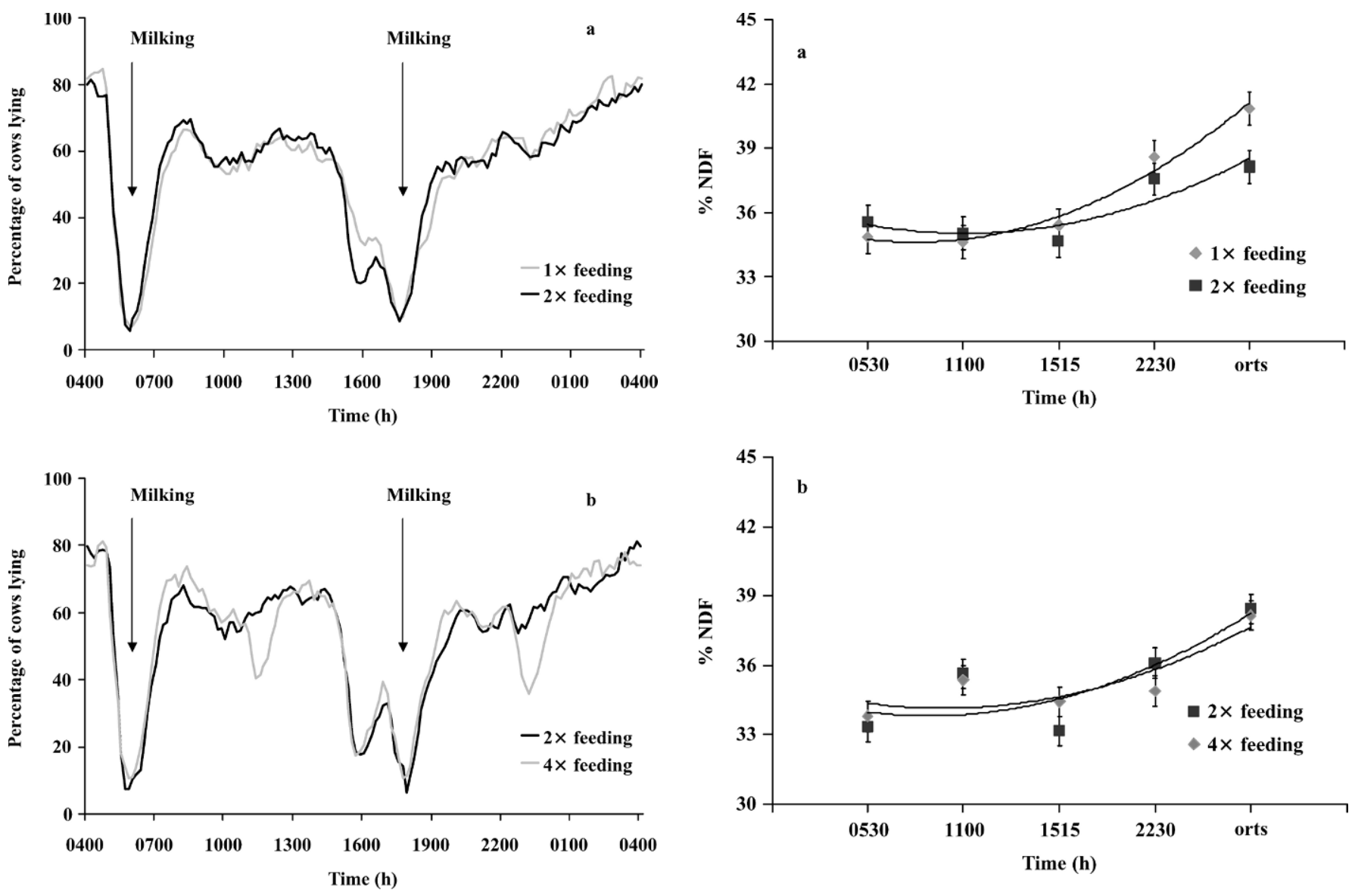

Figure 2. Percentage of cows per group lying down over a 24-h period (percentage for each 10-min interval during the day) in a) experiment 1 for 2 treatments (cows fed at $0530 \mathrm{~h}$ and cows fed at 0530 and $1515 \mathrm{~h}$ ) and b) experiment 2 for 2 treatments (cows fed at 0530 and $1515 \mathrm{~h}$ and cows fed at $0530,1100,1515$, and $2230 \mathrm{~h}$ ). Data are averaged for $7 \mathrm{~d}$ per treatment for 4 groups, each containing 12 cows.

lated to have a forage-to-concentrate ratio of 58:42 and $57: 43$ for the $2 \times$ and $4 \times$ treatments, respectively.

\section{DISCUSSION}

During the past few years, there has been increased interest in determining the effects that frequency of feed delivery has on lactating dairy cattle. This interest, in part, may be attributed to many producers who have elected to deliver the daily allotment of TMR $1 \times$ as a means of reducing labor costs. Previous research in this area has been focused on the effects on milk production and DMI; variable results were reported (Gibson, 1984; Nocek and Braund, 1985; Shabi et al., 1999; Dhiman et al., 2002). Much of this variation can be attributed to differences in methodology (e.g., experimental procedures, breeds of cows, diet composition, feeding level). Furthermore, the majority of the experimental condi-

Figure 3. Percentage NDF (DM basis) of the TMR in the feed bunk over the course of the day for a) 2 treatments (cows fed at 0530 $\mathrm{h}$ and cows fed at 0530 and $1515 \mathrm{~h}$ ) and b) 2 treatments (cows fed at 0530 and $1515 \mathrm{~h}$ and cows fed at $0530,1100,1515$, and $2230 \mathrm{~h}$ ). Data are averaged for $4 \mathrm{~d}$ per treatment for 4 groups, each containing 12 cows. For each treatment, data are fitted with predicted quadratic functions.

tions described in these studies (e.g., tie-stall housing) may not be applicable to today's dairy operations. Many modern dairy operators group-house their dairy cattle in free-stall barns. It can be surmised that the frequency of feed delivery may have different effects for group-housed cattle, specifically because of the social facilitation that exists in this setting (Miller and WoodGush, 1991). From the literature, there is little indication of what effect frequency of feed delivery has on the behavior of group-housed lactating dairy cattle.

In the present study, it was evident that grouphoused dairy cows increased their daily feeding time with increased frequency of feed delivery. This finding contradicts previous work reported by Phillips and Rind (2001), who compared the effects of $1 \times$ and $4 \times$ feeding on group-housed cattle and found no effect on daily feeding time. This discrepancy in results may be attributed to differences in experimental methodologies and 
conditions present in the 2 studies. Phillips and Rind (2001) based their feeding behavior data on only $1 \mathrm{~d}$ of observations per treatment. Unfortunately, because there is considerable within-cow day-to-day variation in feeding behavior data, statistical significance in studies based on $1 \mathrm{~d}$ of data can only be achieved when treatment differences are large (Dado and Allen, 1994). Further, the DMI and production level of the cows were very low in comparison with that observed in the present study. Cows with low DMI and milk production may not have the same motivation to feed and, therefore, may not respond to increased frequency of feed delivery by increasing their feeding time as much as cows with high DMI and milk production. Time spent feeding has also been shown to be correlated with milk production (Shabi et al., 2005). It follows that milk production may be increased by encouraging cows to spend more time feeding (Shabi et al., 2005). Therefore, it is possible that the high feeding times observed in the present study in response to high frequency of feed delivery could translate into increased milk production over a longer period of time.

In both experiments 1 and 2, most of the daily increase in feeding time in response to increased frequency of feed delivery was the result of an increase in feeding time during the late evening and early morning hours (i.e., 2000 to $0600 \mathrm{~h}$ ). This result agrees with the finding of Phillips and Rind (2001), who reported that cows that were fed frequently tended to spend less time feeding in the morning and a longer time feeding in the late evening.

Several researchers have shown that increasing frequency of feed delivery can reduce the diurnal fluctuations in rumen $\mathrm{pH}$. French and Kennelly (1990) found that the postprandial $\mathrm{pH}$ in dairy cows fed concentrate $2 \times$ was depressed for a few hours before returning to the prefeeding values. In that same study, the postprandial decline in rumen $\mathrm{pH}$ was virtually eliminated when animals were fed concentrate $12 \times /$ d. Similarly, Shabi et al. (1999) compared $2 \times$ to $4 \times$ feeding of a TMR and found that the diurnal variation in ruminal $\mathrm{pH}$ was significantly reduced when lactating cows were fed $4 \times$. In the present study, increasing the frequency of feed delivery resulted in a more even distribution of feeding time over the course of the day, which may contribute to decreased diurnal variation in ruminal $\mathrm{pH}$ and possibly reduce the risk for subacute ruminal acidosis.

The regression analysis of the data from the peak feeding periods in experiments 1 and 2 indicated that those cows with high feeding times when fed $1 \times$ and $2 \times$ decreased their feeding times when fed $2 \times$ and $4 \times$, respectively. However, it also indicated that those cows with low feeding times when fed $1 \times$ and $2 \times$ increased their feeding times during these periods when fed $2 \times$ and $4 \times$, respectively. These results indicate that increasing the frequency of feed delivery allows for more equal access to fresh feed. This is particularly important, as it has been demonstrated that the delivery of fresh feed has the greatest effect in terms of stimulating feeding activity in group-housed dairy cattle (DeVries and von Keyserlingk, 2005).

In both experiments 1 and 2, group feed intakes were used to calculate the average DMI per cow per treatment, and we found no effect of treatment on this measure for either experiment. However, we caution the interpretation of these results, as these experiments were designed to test predictions concerning feeding behavior and do not provide a strong test of intake differences. The regression analysis of the feeding behavior data indicated that cows varied in their distribution of daily feeding time, and this same variation may also have occurred in the distribution of DMI.

It is interesting to note that in both experiments, despite the increases in feeding time with increased frequency of feed delivery, there was no change in total daily lying time. This result indicates that with increased frequency of feed delivery, cows are able to increase the amount of time that they spend feeding and reduce the amount of time that they spend idly waiting for feed or to access the feed bunk. The daily distribution of lying time was, however, influenced by frequency of feed delivery. In experiment 1 , the cows took 13 min longer to lie down after the a.m. milking when fed $1 \times$ compared with when fed $2 \times$. This reflected the tendency for cows to spend a longer time feeding during the 90-min period following feed delivery when they were fed $1 \times$. Interestingly, the latency to lie down after the p.m. milking was not different between the $1 \times$ and $2 \times$ treatments. This is most likely due to the fact that when cows were fed $2 \times$, they had $>90 \mathrm{~min}$ of access to their second daily delivery of feed prior to going to the milk parlor. In experiment 2 , when the cows were fed $2 \times$, they took 11 min longer to lie down after milking compared with when they were fed $4 \times$. Again, this reflects the fact that when the cows were fed $4 \times$, they reduced the time they spent feeding during the 90-min period following feed delivery. This further demonstrates that the cows more evenly distributed their feeding time over the course of the day when feed was delivered at a higher frequency.

The frequency of feed delivery did not affect the daily incidence of aggressive interactions at the feed bunk in either experiment. This result agrees with the finding of Phillips and Rind (2001), who reported no effect of frequency of feed delivery on the daily number of aggressive interactions. Despite this, the regression analyses undertaken in both experiments indicated that the cows in the present study that were displaced least 
often from the feed bunk during the low frequency of feed delivery treatment were displaced at a slightly higher frequency when exposed to the higher frequency of feed delivery treatments. The analyses also indicated that the cows that were displaced at the highest rate during the low frequency treatment, in each experiment, were displaced much less frequently when exposed to the higher frequency of feed delivery treatments. Therefore, the subordinate cows were not displaced as frequently when they were fed more often. This finding indicates that increasing the frequency of feed delivery may be particularly useful in allowing all cows to feed when they want to, without the fear of being displaced.

Leonardi et al. (2005) suggest that longer particles are typically higher in NDF concentration than the TMR; therefore, refusal of long particles can reduce total NDF intake. Further, several researchers have demonstrated that sorting can be signified by disparities between NDF concentrations in the diet and the orts (Kononoff et al., 2003; Kononoff and Heinrichs, 2003; Onetti et al., 2004). Therefore, to assess the extent of sorting of the TMR in the present study, the NDF content of the TMR in the feed bunk was measured throughout the day. The analyses demonstrated that the NDF content of the TMR in the feed bunk increased in a curvilinear manner throughout the day for all treatments in both experiments. Similarly, in a study by Kononoff et al. (2003), where cows were fed $1 \times$, it was demonstrated that the NDF content of the feed present in the bunk increased throughout the day following the initial feed delivery, indicating that feeding sorting had occurred.

In the present study, comparison of the calculated forage-to-concentrate ratio of the delivered feed and the orts in both treatments in each experiment also provides further evidence that sorting of the diet can lead to the cows consuming an inconsistent ration, as suggested by Stone (2004). Sorting typically occurs when cows discriminate against the longer forage components, resulting in some cows consuming much more grain than intended (Leonardi and Armentano, 2003). It is believed that cows consuming the increased amounts of grain and low amounts of fiber in situations where sorting behavior is evident are at increased risk for subacute ruminal acidosis (Cook et al., 2004; Stone, 2004). Alternatively, sorting of the TMR can reduce the quality of the feed, particularly in the later hours past the time of feed delivery, as observed in the present study. This may be detrimental for those cows that do not have access to feed at the time when it is delivered. In such cases, these cows may not be able to maintain adequate nutrient intake to maintain high levels of milk production. The results of the present study indi- cate that increasing the frequency of feed delivery allows for more equal access to feed. The regression analyses of the feeding data during both the post feed delivery and peak feeding periods and the late evening and early morning hours indicated that the higher frequency of feeding treatment, in each experiment, resulted in more equal feeding times between cows during these periods. This result coupled with the finding that subordinate cows were not displaced as frequently when fed more often, indicate that providing feed more frequently may improve access to feed for all cows, especially during peak feeding periods when fresh feed is available. Therefore, higher frequencies of feed delivery have the potential to reduce the variation in diet quality consumed by the cows.

Improving access to feed may be particularly important when feed is delivered at low frequencies. In experiment 1 , the interaction between the TMR sampling time and frequency of feed delivery indicated that more sorting occurred when feed was delivered $1 \times$. This translated into the orts containing $8 \%$ more forage when the cows were fed $1 \times$ compared with $2 \times$. This result supports the suggestion by Shaver (2002) that the effect of sorting is greater when frequency of feed delivery is low. Therefore, the amount of sorting of a TMR by lactating dairy cows can be reduced by increasing the frequency of feed delivery from $1 \times$ to $2 \times$.

\section{CONCLUSIONS}

In both experiments 1 and 2 , increasing the frequency of feed delivery from $1 \times$ to $2 \times$ and $2 \times$ to $4 \times$, respectively, allowed the cows to increase their daily feeding time and increase the distribution of feeding time over the course of the day. The changes in distribution of feeding time resulted in cows having more equal access to feed. The frequency of feed delivery did not affect the daily incidence of aggressive interactions at the feed bunk in either experiment. Despite this, we did find that subordinate cows were not displaced as frequently when fed more often. For all treatments in both experiments, the NDF content of the TMR in the feed bunk increased throughout the day, indicating that sorting of the TMR occurred. Additionally, the amount of sorting of a TMR was reduced by increasing the frequency of feed delivery from $1 \times$ to $2 \times$. We, therefore, recommend delivering feed frequently to improve access to fresh feed for all cows and to reduce sorting. This will potentially reduce the variation in diet quality consumed by the cows.

\section{ACKNOWLEDGMENTS}

We thank the staff and students at The University of British Columbia's Dairy Education and Research 
Centre and the University's Animal Welfare Program. In particular, we thank Danica Olenick, Kiyomi Ito, and Dineke van den Hazel for their help with running the experiments and with the video analysis. We also thank Bev Farr and Alastair Furtado of the Lethbridge Research Centre for their assistance in performing laboratory analyses. Trevor DeVries was supported by a Natural Sciences and Engineering Research Council of Canada (NSERC) Canada Graduate Scholarship. The project was funded by the Agriculture and Agri-Food Canada/NSERC Research Partnership Support Program made possible by contributions from the Dairy Farmers of Canada.

\section{REFERENCES}

Association of Official Analytical Chemists. 1990. Official Methods of Analysis. Assoc. Off. Anal. Chem., Arlington, VA.

Canadian Council on Animal Care. 1993. Guide to the Care and Use of Experimental Animals. Vol. 1. E. D. Olfert, B. M. Cross, and A. A. McWilliam, ed. CCAC, Ottawa, Canada.

Cook, N. B., K. V. Nordlund, and G. R. Oetzel. 2004. Environmental influences on claw horn lesions associated with laminitis and subacute ruminal acidosis in dairy cows. J. Dairy Sci. 87(E. Suppl.):E36-E46.

Dado, R. G., and M. S. Allen. 1994. Variation in and relationships among feeding, chewing, and drinking variables for lactating dairy cows. J. Dairy Sci. 77:132-144.

DeVries, T. J., and M. A. G. von Keyserlingk. 2005. Time of feed delivery affects the feeding and lying patterns of dairy cows. J. Dairy Sci. 88:625-631.

DeVries, T. J., M. A. G. von Keyserlingk, and K. A. Beauchemin. 2003a. Diurnal feeding pattern of lactating dairy cows. J. Dairy Sci. 86:4079-4082.

DeVries, T. J., M. A. G. von Keyserlingk, and D. M. Weary. 2004. Effect of feeding space on the inter-cow distance, aggression, and feeding behavior of free-stall housed Holstein dairy cows. J. Dairy Sci. 87:1432-1438.

DeVries, T. J., M. A. G. von Keyserlingk, D. M. Weary, and K. A. Beauchemin. 2003b. Measuring the feeding behavior of lactating dairy cows in early to peak lactation. J. Dairy Sci. 86:3354-3361.

Dhiman, T. R., M. S. Zaman, I. S. MacQueen, and R. L. Boman. 2002. Influence of corn processing and frequency of feeding on cow performance. J. Dairy Sci. 85:217-226.

Endres, M. I., T. J. DeVries, M. A. G. von Keyserlingk, and D. M. Weary. 2005. Effect of feed barrier design on the behavior of loosehoused lactating dairy cows. J. Dairy Sci. 88:2377-2380.

Fregonesi, J. A., C. B. Tucker, D. M. Weary, F. C. Flower, and T. Vittie. 2004. Effect of rubber flooring in front of the feed bunk on the behavior of dairy cattle. J. Dairy Sci. 87:1203-1207.

French, N., and J. J. Kennelly. 1990. Effects of feeding frequency on ruminal parameters, plasma insulin, milk yield, and milk composition in Holstein cows. J. Dairy Sci. 73:1857-1863.
Gibson, J. P. 1984. The effects of frequency of feeding on milk production of dairy cattle: An analysis of published results. Anim. Prod. 38:181-189.

Grant, R. J., and J. L. Albright. 2000. Feeding behaviour. Pages 365382 in Farm Animal Metabolism and Nutrition. J. P. F. D’Mello, ed. CABI Publishing, Wallingford, Oxon, UK.

Jezierski, T. A., and M. Podluzny. 1984. A quantitative analysis of social behaviour of different crossbreds of dairy cattle kept in loose housing and its relationship to productivity. Appl. Anim. Behav. Sci. 13:31-40.

Kononoff, P. J., and A. J. Heinrichs. 2003. The effect of corn silage particle size and cottonseed hulls on cows in early lactation. J. Dairy Sci. 86:2438-2451.

Kononoff, P. J., A. J. Heinrichs, and H. A. Lehman. 2003. The effect of corn silage particle size on eating behavior, chewing activities, and rumen fermentation in lactating dairy cows. J. Dairy Sci. 86:3343-3353.

Leonardi, C., and L. E. Armentano. 2003. Effect of quantity, quality, and length of alfalfa hay on selective consumption by dairy cows. J. Dairy Sci. 86:557-564.

Leonardi, C., F. Giannico, and L. E. Armentano. 2005. Effect of water addition on selective consumption (sorting) of dry diets by dairy cattle. J. Dairy Sci. 88:1043-1049.

Miller, K., and D. G. M. Wood-Gush. 1991. Some effects of housing on the social behaviour of dairy cows. Anim. Prod. 53:271-278.

National Research Council. 2001. Nutrient Requirements for Dairy Cattle. Natl. Acad. Sci. Washington, DC.

Nocek, J. E., and D. G. Braund. 1985. Effect of feeding frequency on diurnal dry matter and water consumption, liquid dilution rate, and milk yield in first lactation. J. Dairy Sci. 68:2238-2247.

Onetti, S. G., S. M. Reynal, and R. R. Grummer. 2004. Effect of alfalfa forage preservation method and particle length on performance of dairy cows fed corn silage-based diets and tallow. J. Dairy Sci. 87:652-664.

Phillips, C. J. C., and M. I. Rind. 2001. The effects of frequency of feeding a total mixed ration on the production and behavior of dairy cows. J. Dairy Sci. 84:1979-1987.

SAS Institute Inc. 1999. SAS User's Guide. SAS Institute Inc., Cary, NC.

Shabi, Z., I. Bruckental, S. Zamwell, H. Tagari, and A. Arieli. 1999. Effects of extrusion of grain and feeding frequency on rumen fermentation, nutrient digestibility, and milk yield and composition in dairy cows. J. Dairy Sci. 82:1252-1260.

Shabi, Z., M. R. Murphy, and U. Moallem. 2005. Within-day feeding behavior of lactating dairy cows measured using a real-time control system. J. Dairy Sci. 88:1848-1854.

Shaver, R. D. 2002. Rumen acidosis in dairy cattle: Bunk management considerations. Adv. Dairy Technol. 14:241-249. University of Alberta, Edmonton, Alberta, Canada.

Stone, W. C. 2004. Nutritional approaches to minimize subacute ruminal acidosis and laminitis in dairy cattle. J. Dairy Sci. 87(E. Suppl.):E13-E26.

Van Soest, P. J., J. B. Robertson, and B. A. Lewis. 1991. Methods for dietary fiber, neutral detergent fiber and non-starch polysaccharide in relation to animal nutrition. J. Dairy Sci. 74:35833597. 